\section{The natural oestrogenic hormone oestradiol as a new component of combined oral contraceptives}

Thromboembolism is a rare but serious side effect of combined oral contraceptive use. Astedt et $a^{1}{ }^{1}$ showed a defect in the fibrinolytic system in women who had had deep vein thrombosis when using combined oral contraceptives, especially in the fibrinolytic activator content in the vessel walls, which activates this defence system against thrombosis. The synthetic oestrogenic compound ethinyloestradiol depresses the activator content of the vessel walls." Biologically equivalent doses of the natural oestrogenic hormone oestradiol, however, do not have this effect. ${ }^{3}$ Oestradiol impairs liver function less than synthetic oestrogens ${ }^{4}$ and might therefore be a safer component of oral contraceptives. ${ }^{5}$

We undertook a pilot study of the side effects of an oral contraceptive pill containing oestradiol and norethisterone to find out whether natural oestrogen might be useful in the development of a new pill.

\section{Subjects, methods, and results}

The pill contained $4 \mathrm{mg}$ of micronised oestradiol and $3 \mathrm{mg}$ norethisterone (Netagen; Novo Pharmaceuticals, Denmark). It was taken for 21 days and then withdrawn for seven days of consecutive cycles. The study was approved by the Swedish Medical and Social Welfare Board. Volunteers were 25 normally menstruating, apparently healthy women of whom 17 had never used combined oral contraceptives before, five had previously used them, and three had been taking pure gestagenic preparations. The study lasted for one year, during which time the women were asked to note bleeding abnormalities, amenorrhoea, dysmenorrhoea, premenstrual tension, nausea, and emotional disturbances. Weight gain of more than $2 \mathrm{~kg}$ and an increase in systolic or diastolic blood pressure of more than $10 \mathrm{~mm} \mathrm{Hg}$ were recorded.

No pregnancies or thromboembolic incidents occurred during the study (204 cyrles). Spotting occurred in seven women, mainly during the first cycle, and never after the third. Two women developed amenorrhoea, one of whom had previously had amenorrhoea before and during the use of conventional combined oral contraceptives. Two women had dysmenorrhoea, but had had similar pain before they used the pill. Emotional disturbances were noted by two. Premenstrual tension or nausea did not occur. The menstrual flow was described as unchanged by 12 and decreased by the remaining 13. Body weight increased $(>2 \mathrm{~kg})$ in four, remained unchanged in 19 , and decreased in two. No increase in blood pressure was recorded.

Eleven of the women stopped taking the pill after 3-6 months, five because of desired pregnancy, two because of amenorrhoea, one because of spotting, one because of continued dysmenorrhoea, and two because of emotional disturbances. Fourteen women continued taking Netagen, were satisfied, and felt well.

\section{Comment}

Oestradiol is a natural oestrogen obtained from soya beans. It has hitherto proved unsuitable for use in combined oral contraceptives as it is not readily absorbed. This problem has, however, been resolved by the new micronising technique.

Although six of the 25 volunteers stopped taking Netagen because of side effects, five of them had had similar complaints when using conventional combined oral contraceptives or no pill at all. Only one of the cases of amenorrhoea could be ascribed to Netagen. It should also be pointed out that eight of the 25 women were using or had used various combined oral contraceptives or pure gestangenic pills before the trial, and most of these wanted to try the new pill because of side effects associated with these preparations.

The amounts and balance of oestradiol and norethisterone in the Netagen were probably not ideal and may require adjustment. But since oestradiol seems less likely to cause thromboembolic complications, the results of this pilot study suggest that it may be useful as a new component of combined oral contraceptives.

\footnotetext{
1 Astedt, B, et al, British Medical fournal, 1973, 4, 631.

2 Åstedt, B, Acta Obstetrica et Gynecologica Scandinavica, 1971, 50, 279.
}

3 Astedt, B, and Jeppsson, S, Fournal of Obstetrics and Gynaecology of the British Commonwealth, 1974, 81, 719.

4 Jeppsson, S, and Rannevik, G, British fournal of Obstetrics and Gynaecology, $1976,83,567$.

5 Astedt, B, American Heart fournal, 1975, 90, 1.

(Accepted 29 October 1976)

Department of Gynaecology and Obstetrics, University of Lund, Allmanna Sjukhuset, Malmö, S-214 01 Malmö, Sweden

B ÅSTEDT, MD, associate professor

L SVANBERG, MD, associate professor

$S$ JEPPSSON, MD, senior gynaecologist

P LIEDHOLM, MD, associate professor

G RANNEVIK, MD, senior gynaecologist

\section{Anterior tibial compartment syndrome associated with alcohol abuse}

The anterior tibial compartment syndrome is a rare conditior characterised by severe pain over the anterolateral aspect of the calves followed by footdrop. Histologically there is ischaemic necrosis of the anterior tibial muscles. There are many predisposing factors, of which exercise is the commonest. ${ }^{12}$

We report a case associated with alcohol abuse. Although acute in onset, the condition was painless owing to a coexistent peripheral neuropathy.

\section{Case report}

A 55-year-old man presented with a 30-hour history of progressive difficulty in walking culminating in a fall from which he was unable to rise. He had noticed tingling in his feet but no pain. For 35 years he had drunk 10 pints $(5.7 \mathrm{l})$ of beer and half a bottle of sherry daily. There had been a gradual increase in his consumption before admission but no recent "binge." He was taking lithium carbonate for a manic depressive illness.

On examination he looked unwell and his temperature was $38^{\circ} \mathrm{C}$. The anterolateral aspects of both calves were red, warm, and tense, though not tender. Neurological abnormalities were confined to the legs and consisted of moderate weakness of hip flexion and absent dorsiflexion at both ankles; deep pain was absent, and touch, pin-prick, and temperature appreciation were reduced below the knees; vibration and position sense were diminished in the toes; ankle jerks were absent.

Haemoglobin was $15.2 \mathrm{~g} / \mathrm{dl}$, erythrocyte sedimentation rate $38 \mathrm{~mm}$ in the first hour (Westergren), fasting pyruvate $100 \mu \mathrm{mol} / 1 \quad(0.9 \mathrm{mg} / 100 \mathrm{ml})$ (normal $45-80 \mu \mathrm{mol} / 1 ; 0.4-0.7 \mathrm{mg} / 100 \mathrm{ml}$ ), and creatine phosphokinase $2250 \mathrm{U} / 1$ (normal up to $80 \mathrm{U} / \mathrm{l}$ ). Serum lithium was within the therapeutic range. Electromyography showed polyphasic units of short and long duration in the right gastrocnemius, quadriceps, and tibialis anterior; motor nerve conduction velocities were normal; and ulnar and median sensory nerve action potentials were reduced in amplitude. Biopsy of extensor hallucis longus showed infarcted muscle.

After alcohol withdrawal and treatment with Parentrovite his neuropathy improved, and two weeks later the only abnormalities were bilateral footdrop and impaired deep pain sensation below the knees. Creatine phosphokinase had fallen to $270 \mathrm{U} / 1$ and the fasting pyruvate was within normal limits. Two months later the footdrop was unchanged.

\section{Comment}

This case is unusual for two reasons. Firstly, alcohol abuse seems to have been the cause of the anterior tibial compartment syndrome, and this has not previously been reported. Certainly none of the known causes of the syndrome were present, and it seems unlikely 

cause an acute muscular syndrome ${ }^{3}$ but this is usually painful, asymmetrical, and associated with a recent binge. Secondly, pain is usually the initial symptom of the anterior tibial compartment syndrome and has been thought to be a constant finding. ${ }^{2}$ In this case pain was absent because of the coexistence of a peripheral neuropathy. Again, alcohol abuse was the probable cause of this, as it was reversible with alcohol withdrawal and vitamin supplementation.

\section{${ }^{1}$ Bradley, E L, Surgery, Gynecology and Obstetrics, 1973, 136, 289.}

${ }^{2}$ Lees, A, fournal of Neurology, Neurosurgery and Psychiatry, 1976, 39, 406.

${ }^{3}$ Hed, R, et al, Acta Medica Scandinavica, 1962, 171, 585.

Department of Neurology, North Staffordshire Hospital Centre, Stoke-on-Trent ST4 7LN

V H PATTERSON, MB, MRCP, registrar

H G BODDIE, MB, MRCP, consultant neurologist that lithium carbonate was implicated. Alcohol excess is known to

(Accepted 28 October 1976)

neck, external sphincter, and pelvic floor. Infection of residual urine is common, particularly in women. Both of our patients had chronically inflamed bladders. Furthermore, the presence of hypertrophy and trabeculation of the bladder wall in both cases is highly suggestive of chronic outflow obstruction.

Factors other than chronic cystitis and outflow obstruction may have contributed to bladder rupture in case 2 . Catheterisation has been reported as causing bladder perforation. ${ }^{3}$ This patient was also given a parasympathomimetic drug, which, although useful in chronic hypotonic bladder dysfunction, is contraindicated when the bladder neck is obstructed.

Spontaneous bladder rupture is rarely diagnosed before laparotomy, and mortality is high. Our two patients had severe sensory loss, which would favour a late presentation. The use of corticotrophin in case 2 may well have masked the signs of peritonitis and further delayed the diagnosis.

1 Bastable, J R G, de Jode, L R, and Warren, R P, British fournal of Urology, 1959, 31, 78.

${ }^{2}$ Miller, H, Simpson, C A, and Yeates, W K, British Medical Fournal, 1965, $2,1265$.

${ }^{3}$ Hughes, J W, Gambee, J, and Edwards, C, fournal of Urology, 1973, 109, 237.

${ }^{4}$ Lee, L W, fournal of Urology, 1949, 62, 300.

(Accepted 19 October 1976)

Department of Medicine, Royal Free Hospital, London NW3 2QG

ANITA E HARDING, MB, BS, house officer (now senior house officer, department of medicine, Gordon Hospital, London SW1V 2RF)

JAMES SCOTT, BSC, MRCP, registrar

Queen Elizabeth Hospital, Birmingham B15 2TH

MICHAEL JEFFERSON, DM, FRCP, consultant neurologist

\section{Case reports}

Case 1-A 52-year-old woman presented with a two-day history of haematuria, dysuria, and frequency. She had had difficulty in walking and urgency for five years. On examination she was dehydrated and had loin and abdominal tenderness. She soon became shocked and febrile, and laparotomy showed extensive peritonitis. The bladder was inflamed, hypertrophic, and perforated through the fundus. Neurological assessment during convalescence showed bilateral optic atrophy, spastic tetraparesis, and loss of vibration sense below the iliac crests. Cerebrospinal fluid protein was $0.6 \mathrm{~g} / \mathrm{l}$ and $\mathrm{IgG}$ $0.11 \mathrm{~g} / 1$.

Case 2-A 47-year-old woman who had had multiple sclerosis for 11 years presented with vomiting, abdominal pain, and haematuria. She had had recurrent urinary tract infections and urgency for two years. Two weeks before admission she had become incontinent of urine and an exacerbation of her leg weakness had occurred. She was catheterised and treated with distigmine and corticotrophin. On examination she was febrile and dehydrated and had a distended abdomen and loin tenderness. There was noticeable spasticity of all four limbs and optic atrophy. Abdominal radiography showed fluid levels and gas under the diaphragm. At laparotomy peritonitis and a large, trabeculated, hypertrophic bladder with a perforation in the fundus were found.

\section{Discussion}

Reflection suggests that rupture of the bladder in multiple sclerosis could result from a combination of several factors. Outflow obstruction from neurogenic sphincter disturbance, chronic bladder infection, direct mechanical trauma from an indwelling catheter, and potentiation of infection by corticotrophin may all play a part. Bladder rupture occurred as a presenting feature in case 1 , which further illustrates the need for full neurological assessment of patients, particularly women, who present with retention and chronic infection.

Spontaneous as opposed to traumatic rupture of the bladder is uncommon. Bastable et $a l^{1}$ reviewed 66 cases in 1959. Four patients had neurological disorders, one with paraplegia and three with tabes dorsalis. Most patients had either bladder outflow obstruction or disease of the bladder wall. It appears that these and other factors were present in combination in our two patients.

Urinary symptoms occur in up to $75 \%$ of patients with multiple sclerosis, particularly in those with spasticity and sensory loss in the legs. ${ }^{2}$ Symptoms had been present in both of our patients for at least two years. The nature of the bladder dysfunction in multiple sclerosis is complex because of the multiple lesions at different levels in the nervous system. Bladder outflow obstruction may be caused by corticospinal lesions giving rise to spasm of striated muscle in the bladder

\section{Mesangiocapillary (membranoproliferative) glomerulonephritis and rheumatoid arthritis}

Mesangiocapillary (membranoproliferative) glomerulonephritis (MCGN) is characterised by hypocomplementaemia, proliferation of mesangial cells, and thickening of the glomerular capillary wall. The aetiology is uncertain but it has occurred after upper respiratory tract infection and in systemic lupus erythematosus (SLE), anaphylactoid purpura, chronic bacteraemia, and partial lipodystrophy ${ }^{1} \cdot 2$

A 64-year-old Chinese woman gave a three-year history of morning stiffness and polyarthritis affecting the ankles, wrists, and proximal interphalangeal joints of the hands, for which she occasionally took prednisolone ( $5 \mathrm{mg} /$ day), ketoprofen $(200 \mathrm{mg} /$ day), and phenylbutazone ( $200 \mathrm{mg} /$ day). Six months before admission to hospital she developed generalised oedema followed by painless haematuria. She had generalised oedema, pallor, and a blood pressure of $190 / 100 \mathrm{~mm} \mathrm{Hg}$. The fingers showed spindling of all the interphalangeal joints. The wrists and ankles were swollen and movement was limited.

Analysis of urine showed: red blood cells $112 \times 10^{3} / 1$, white blood cells $95 \times 10^{3} / 1$, and granular casts. Urinary protein was $4 \mathrm{~g} / 24 \mathrm{~h}$, serum albumin $19 \mathrm{~g} / \mathrm{l}$, serum creatinine $194 \mu \mathrm{mol} / 1(2 \cdot 2 \mathrm{mg} / 100 \mathrm{ml})$, and haemoglobin $9.5 \mathrm{~g} / \mathrm{dl}$. Serum C3 was less than $0.05 \mathrm{~g} / 1$ (normal $0.9-1.2 \mathrm{~g} / \mathrm{l}$ ) and C4 $0 \cdot 24 \mathrm{~g} / 1$ (normal $0 \cdot 2-0 \cdot 4 \mathrm{~g} / \mathrm{l}$ ). Four tests for LE cells gave negative results. Antinuclear antibody was absent. A latex test for rheumatoid factor gave a titre of $1 / 40$ (normal $<1 / 32$ ).

$X$-ray pictures of the hands and wrists showed reduced joint space, marginal erosions, periarticular osteoporosis, and articular destruction. Renal biopsy showed 15 swollen and lobulated glomeruli with hypercellularity from mesangial cell proliferation. The mesangial matrix was increased. The glomerular lumina were narrowed and many were obliterated. The capillary basement membranes were fragmented and showed a double-contour appearance in places (see figure). The diagnosis of MCGN was confirmed on electron microscopy. We report a case in a patient with rheumatoid arthritis.

\section{Case report}

